\title{
Study on the basic characteristics of MSWI fly ash in northern China
}

\author{
Jianguo Zhou \\ School of Environmental Science and Engineering, Tianjin University, Tianjin 300072, China
}

Tianjin Esun Environmental technology Co. LTD, Tianjin 300384, China

School of Science, Tianjin Chengjian University, Tianjin 300384, China

Shuguang Zhang and Ping Li

Tianjin Esun Environmental technology Co. LTD, Tianjin 300384, China

\begin{abstract}
Fly ash sample collected from a facility which treat urban waste with combustion, the major physio-chemical features of which were studied including chemical composition; the heavy-metal content, speciation as well as leaching toxicity; surface morphology analysis and composition within the mineralogical phase using XRF, ICP, SEM and XRD. Results from the experiments indicate that the primary elements contained in the fly ash are $\mathrm{Cl}, \mathrm{K}, \mathrm{Na}, \mathrm{S}, \mathrm{Ca}$ and $\mathrm{Si}$, and $\mathrm{Zn}, \mathrm{Pb}$ and $\mathrm{Cu}$ all belong to the category of primary heavy metals. Crystalline phase's analysis demonstrated that the fly ash is primarily composed of some soluble salts like $\mathrm{KCl}, \mathrm{NaCl}$ and some crystals as $\mathrm{SiO} 2$ and $\mathrm{CaSO} 4$. In terms of morphology of the fly ash, it is irregular, along with aggregation of both amorphous structures and polycrystalline. This structure makes the fly ash strong adsorption capacity on heavy metals, dioxin and other pollutants. The leaching toxities of all the observed elements of $\mathrm{Zn}, \mathrm{Cu}, \mathrm{Pb}, \mathrm{Ni}, \mathrm{Cd}$ have all exceeded the limits of Landfill Waste Requirement in China (GB16889-2008) and the leachate concentration realated to $\mathrm{Pb}, \mathrm{Zn}, \mathrm{Cd}$ have also exceeded the limitation of Chinese Identification Standard for Hazardous Wastes (GB5085.3-2007). According to the results of sequential extraction, high mobililty of $\mathrm{Cd}, \mathrm{Pb}$ and $\mathrm{Zn}$ has been discovered in this research. Consequently, this could pose a threat to the surroundings when MSWI fly ash is landfilled or reutilized.
\end{abstract}

KEYWORD: fly ash; basic characteristics; heavy metals; leaching toxicity; speciation

\section{INTRODUCTION}

In china, a method called incineration which used to treat MSW (Municipal Solid Waste) has now become increasingly important and beneficial for oxidizing the organic materials in the wastes and reducing the volume of the original wastes to a great degree. Unavoidably, fly ash would often be produced in the process of MSW incineration, which could make up $3 \%-5 \%$ in the primary weight. And the fly ash contains a great many materials which are harmful, like toxic organic compounds and leachable heavy metals (X.G. Jiang, 2015). As fly ash has been posing serious threats to the environment because of heavy-metal leaching, persistent organic pollutants together with soluble salts, MSWI fly ash, known as a typical type of hazardous waste, has to be pretreated appropriately with the methods before final disposal or recycling, like thermal treatment, solidification, and chemical stabilization, etc.

In order to treat and dispose MSWI fly ash properly, it is very important to understand the basic properties of fly ash including their morphology, chemical composition, mineral composition and especially, leaching toxicity. In this article, the basic properties of fly ash were investigated systematical- ly, which were intended to be a ground on which the subsequent processing methods would be selected and optimized.

\section{EXPERIMENTAL}

\subsection{Samples}

In this research, the fly ash samples were originally obtained from an urban waste incinerator, which is situated in the north of China. A semi-dry scrubber, an activated carbon sprayer and a bag filter together constitute the APCD (Air Pollution Control Devices). The spray drier and the bag filter, equipment for neutralizing acid gas with the assistance of hydrated lime slurry and for gathering particulates respectively, compose a semi-dry scrubber. During a continuous 7-day period, the fly ash samples were gathered. After collected, the fly ash samples should be homogenized as well as filtered with a 20 -mesh sieve. In the next 24 hours, these samples are dried at the temperature of $105^{\circ} \mathrm{C}$. 


\subsection{Characterization}

\section{Composition and content}

In this research, XRF with apparatus ZSX Primus II assisted with determining the composition and content of the fly ash. This device is a WD- XRF spectrometer with a $\mathrm{Rh}$ anode end-window $\mathrm{X}$ - ray tube equipped with $30 \mu \mathrm{m}$ Be window. The results were expressed in the percentage of corresponding oxides. als.

Content and leaching characteristic of heavy met-

For the sake of acquiring relatively more precise heavy-metal concentrations, microwave together with digesting acid $\left(\mathrm{HNO}_{3} / \mathrm{HCl} / \mathrm{HF}\right)$ in three steps were used to dissolve the fly ash samples. Then ICP (1000II) assists with the determination of the content of heavy metals.

Heavy-metal leaching toxicity determination is in accordance with the Chinese Solid waste-Extraction Procedure for Leaching Toxicity-Acetic Acid Buffer Solution Method (HJ/T 300-2007). Firstly, $75.0 \mathrm{~g}$ dried sample was poured to deionized water of 750 $\mathrm{mL}$ in a 1L bottle made of polyethylene with a solid to liquid ratio of 1:10; subsequently, the polyethylene bottle was fixed in a flip oscillator. Then, it was agitated at a speed of $30 \pm 2 \mathrm{r} / \mathrm{min}$ for $18 \mathrm{~h}$ in succession. After all these, it was placed to stand for $0.5 \mathrm{~h}$; thirdly, vacuum filtration, with the assistance of a 0.45 $\mu \mathrm{m}$-micropore filter membrane, has helped with separating the component which is soluble. Finally, the filtrate was adjusted to a required volume and then the heavy-metal concentrations contained could be detected with the assistance of ICP.

Chemical speciation of heavy metals

Five different fractions, which are named as exchangeable fraction (F1), fraction bound to carbonate (F2), fraction bound to Fe-Mn oxides (F3), fraction bound to organic matters $(\mathrm{F} 4)$ and residual fraction (F5) were classified so as for determining heavy-metal partitioning.

Experimental conducting conditions abide by the details demonstrated in Table 1. Centrifuging would accomplish the process of separating when each one step of extraction is over; and the residual solids were utilized for the successive extractions. For further analysis, $0.5 \mathrm{~mL} \mathrm{HNO}_{3}$ should be added to preserve the supernatant.

Table 1 Experimental conditions in sequential extraction

Chemical fraction
1. Exchangeable
2. Bound to carbonate
3. Bound to Fe-Mn-oxides

4. Bound to organic matters

5. Residual
Morphology of the fly ash was observed with the assistance of SEM. The samples were coated with $\mathrm{Au}$ and then analyzed with the means of a scanning electron microscope Hitachi S-4800 equipped with a Genesis XM2 energy-dispersive spectrometer.

XRD analysis:

The crystalline phases of the fly ash could be analyzed by XRD. XRD analysis was conducted with a $\mathrm{X}^{\prime}$ Pert PRO rotating-target X-ray diffractometer (4 $\mathrm{kV}, 30 \mathrm{~mA}$ ). The samples were put into a sample rack with zero background and the experiments were conducted with the scanning $2 \theta$ angles from $20^{\circ}$ to $80^{\circ}$, a step interval of $0.02^{\circ}$ and a scan speed of $2 \%$ min.

All of the the concentrations mentioned above as well as all the features were regarded as the average values of three parallel experiments.

\section{RESULTS AND DISCUSSION}

\subsection{Composition and content}

Generally, the MSWI fly ash composition is determined by the composition of combusted waste, technology of incineration (equipment for controlling the air pollution, filters' separation efficiency, etc.) and the conditions of redox (K. Martin, 2012).

Chemical composition of the fly ash measured by $\mathrm{XRF}$ is listed in Table 2. The results demonstrate that $\mathrm{Cl}, \mathrm{K}, \mathrm{Na}, \mathrm{S}, \mathrm{Ca}$ and $\mathrm{Si}$ are the primary elements in the fly ash. Particularly, $\mathrm{Cl}, \mathrm{Na}_{2} \mathrm{O}, \mathrm{K}_{2} \mathrm{O}$ and $\mathrm{SO}_{3}$ are found in a relatively high content of $18.95 \%$, $16.61 \%, 15.08 \%$ and $14.36 \%$, respectively. High content of chlorine has a direct relationship with the $\mathrm{PVC}$ in waste plastics and $\mathrm{NaCl}$ in kitchen garbage, which makes up most of the chlorides in MSW. Unfavorable, from the opinion of applying it in concrete, is particularly a relatively great amount of sulfates and chlorides. The sulfates could make the concrete strength decline, while chlorides accelerate 
the steel reinforcement corrosion. The primary heavy-metal elements were $\mathrm{Cu}, \mathrm{Pb}$ and $\mathrm{Zn}$. And the total content of them is less than $5 \%$.The obtained results are compared with the literatures reported by different researchers and are found to be consistent with the existing research reports (R. Ibáňez, 2000).

Table 2 Main composition and content of the fly ash (mass fraction, \%)

\begin{tabular}{cccccccc}
\hline Composition & $\mathrm{CaO}$ & $\mathrm{Cl}$ & $\mathrm{SO}_{3}$ & $\mathrm{Na}_{2} \mathrm{O}$ & $\mathrm{K}_{2} \mathrm{O}$ & $\mathrm{SiO}_{2}$ & $\mathrm{MgO}$ \\
Content & 12.26 & 18.95 & 14.36 & 16.61 & 15.08 & 9.49 & 2.79 \\
\hline Composition & $\mathrm{Al}_{2} \mathrm{O}_{3}$ & $\mathrm{Fe}_{2} \mathrm{O}_{3}$ & $\mathrm{P}_{2} \mathrm{O}_{5}$ & $\mathrm{TiO}_{2}$ & $\mathrm{ZnO}$ & $\mathrm{PbO}$ & $\mathrm{CuO}$ \\
Content & 3.11 & 2.18 & 1.09 & 0.52 & 1.75 & 0.57 & 0.30 \\
\hline
\end{tabular}

\subsection{Content of heavy metals and leaching toxicity}

The most significant indicator, in the process of assessing the environmental impact and offering technical support for treatment, disposal as well as recovery of the fly ash, is the contained heavy metal leaching toxity(A. Zacco, 2014).

The primary heavy metal content as well as leaching characteristics is presented in Table 3 . It demonstrated that the leachate concentrations of $\mathrm{Pb}$, $\mathrm{Zn}, \mathrm{Cd}$ exceed the limits of GB5085.3-2007. In particular, the concentration of $\mathrm{Zn}$ in leachate is 6 times higher than the standard limits; the concentration of $\mathrm{Pb}$ is nearly 15 times greater than the standard lim- its; and the concentration of $\mathrm{Cd}$ is 19 times greater than the identification standard of hazardous wastes. This fact implies that $\mathrm{Pb}, \mathrm{Zn}$ and $\mathrm{Cd}$ have high mobility when contacting with water, and therefore, effective control techniques should be adopted in the MSWI fly ash treatment or disposal.

Meanwhile, the leaching toxicities of $\mathrm{Cu}, \mathrm{Pb}, \mathrm{Zn}$, $\mathrm{Cd}, \mathrm{Ni}$ all exceed the limits of GB16889-2008. In particular, the concentration of $\mathrm{Cd}$ in leachate is nearly 130 times higher than the specified standard limits and the concentration of $\mathrm{Pb}$ is 284 times greater than the standard of GB16889-2008. Therefore, such hazardous waste must be pretreated properly before entering the MSW landfill.

Table 3 Total concentration and leachate concentration of the fly ash

\begin{tabular}{lccccc}
\hline Heavy metal & $\mathrm{Cu}$ & $\mathrm{Pb}$ & $\mathrm{Zn}$ & $\mathrm{Cd}$ & $\mathrm{Ni}$ \\
\hline Total content $/\left(\mathrm{mg} \cdot \mathrm{kg}^{-1}\right)$ & 2106.31 & 5373.36 & 19199.76 & 365.33 & 89.83 \\
Concentration of leachate $/\left(\mathrm{mg} \cdot \mathrm{L}^{-1}\right)$ & 84.50 & 70.88 & 618.75 & 19.36 & 0.91 \\
Standard of GB5085.3-2007/(mg. $\left.\mathrm{L}^{-1}\right)$ & 100 & 5 & 100 & 1 & 5 \\
Standard of GB16889-2008/(mg. $\left.\mathrm{L}^{-1}\right)$ & 40 & 0.25 & 100 & 0.15 & 0.5 \\
\hline
\end{tabular}

\subsection{Chemical speciation of heavy metals}

Metals in exchangeable fraction are considered to be non-specifically absorbed and ion exchangeable, which could be replaced by competing cations. When MSWI fly ash loses its buffering capacity, heavy metals bound to carbonates would be dissolved in acidity conditions. Heavy metals connected to Fe-Mn oxides, which are absorbed in amorphous or weakly-crystal phases, would be released out with the presence of reducing agents. Heavy metals connected to organic matters would be migrated into environment by means of the reactions with oxidants or complexing agents. However, heavy metals in the residual fraction are usually merged into the network of stable crystals, and thus the metals could not be dissolved even in the conditions like destructive acidity (F. Liu, 2004).

In terms of phase distributions of heavy metals, the results are presented in Fig.1. It could be found that the chemical speciation of heavy metals varies largely and exhibit different distribution patterns. In the fly ash sample, $\mathrm{Pb}, \mathrm{Cd}$ and $\mathrm{Zn}$ are primarily contained in the fractions of bound to carbonate and ex- changeable; while $\mathrm{Cu}$ is mostly contained in the last three chemical fractions and $\mathrm{Ni}$ is mainly present in the residual fraction.

According to the sequential extraction results, $\mathrm{Pb}, \mathrm{Zn}$ and $\mathrm{Cd}$ present high leaching potential so that special attention should be given on the landfilling or beneficial reusing of MSWI fly ash and effective techniques should be utilized to avoid the shift of heavy metals based on the detailed chemical analysis.

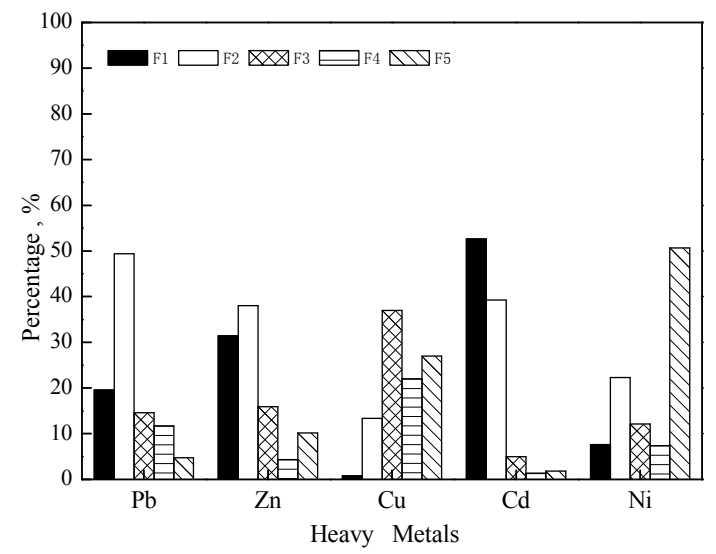

Fig.1 Phase distribution of heavy metals in the fly ash 


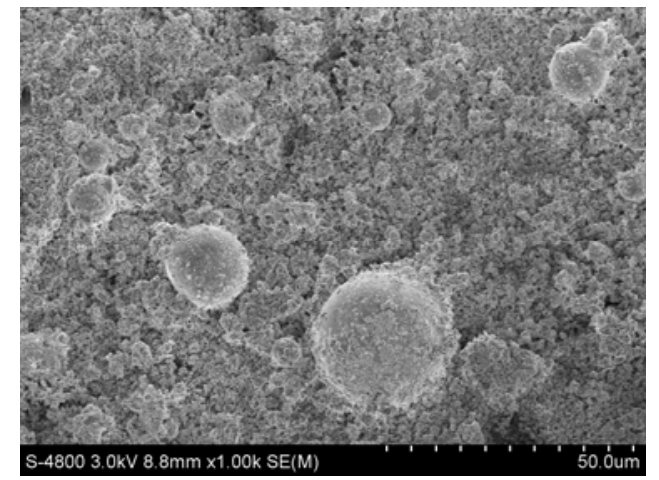

(a)

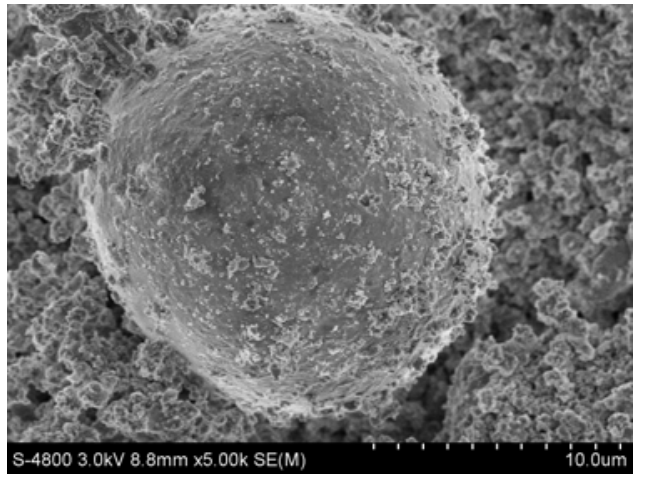

(b)

Fig.2 SEM images of the fly ash

\subsection{SEM observation}

MSWI fly ash is made of very small particles, of which the minimal size or quantity would be very harmful to the environment and human beings. Therefore, it is quite meaningful to explore their microstructures.

Fig. 2 shows that MSWI fly ash was generally anomalous, in shapes of flocculent, flakes or globules. Large quantities of agglomerate network structures were also seen. Generally, they are irregular amorphous forms and polycrystalline aggregates, regular crystals are rarely observed.

Some regular spherical particles are found in Fig. 2(a). The enlargement view of one of these particles is shown in Fig. 2(b). This particle is about $15 \mu \mathrm{m}$ in diameter, with plenty of irregular tinier particulates adhere to the surface, together with a large number of amorphous substances encinctured. The peculiarity that the tiny irregular fly ash particles consist of more tiny irregular amorphous tinier particulates, which show the structure of fly ash is even more complex.

\subsection{XRD analysis}

The identical or similar chemical components can make up different crystalline phases, and different crystalline phases of heavy metals will result in their different leaching toxicities and environmental impacts.
XRD analysis has helped characterizing the crystalling phases in fly ash. Computer program MDI Jade 6.5 has helped processing the XRD patterns. Fig. 3 shows the results of crystalline phases analysis. Results indicated the main species contained in the fly ash are $\mathrm{KCl}, \mathrm{NaCl}, \mathrm{SiO}_{2}$ and $\mathrm{CaSO}_{4}$. The obtained results were similar with the literature reported by different researchers (L. Zhang, 2014).

The crystalline phases of heavy metals were below the detection limits of XRD, probably because MSWI fly ash has very low contents of heavy metals, and they are usually present as complex compounds imbedded in aluminosilicates or silicates, or as amorphous phases. Even if there are certain quantities of crystalline phases, their structures are always too tiny to be detected by XRD.

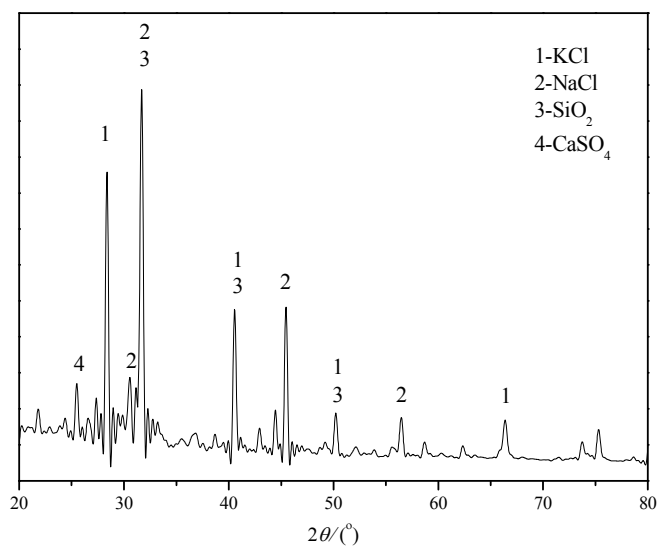

Fig.3 XRD analysis of the fly ash

\section{CONCLUSION}

(1) The major elements in the fly ash are $\mathrm{Cl}, \mathrm{K}$, $\mathrm{Na}, \mathrm{S}, \mathrm{Ca}$ and $\mathrm{Si}$, which accounts for approximately $90 \% . \mathrm{Zn}, \mathrm{Pb}$ and $\mathrm{Cu}$ are the major heavy metals in the fly ash, the total content of which is less than $5 \%$.

(2) The leaching toxicities of five kinds of observed heavy metal including $\mathrm{Cu}, \mathrm{Pb}$ and et al all exceed the limits of GB16889-2008 and the leachate concentration of $\mathrm{Pb}, \mathrm{Zn}, \mathrm{Cd}$ exceed the limitation of GB5085.3-2007. Therefore, effective control techniques should be adopted in the MSWI fly ash treatment and disposal.

(3) Chemical speciation of heavy metals varies largely and exhibits different distribution patterns. In the MSWI fly ash, $\mathrm{Pb}, \mathrm{Cd}$ and $\mathrm{Zn}$ are primarily contained in the carbonate and exchangeable fractions; while $\mathrm{Cu}$ is mostly contained in the last three chemical fractions and $\mathrm{Ni}$ is mainly in the form of residues. In this research, high mobililty for the heavy metals of $\mathrm{Cd}, \mathrm{Pb}$ and $\mathrm{Zn}$ has been discovered. Consequently, this could pose a threat to the environment during the process of landfilling or reutilizing of the fly ash.

(4) In terms of Morphology of the fly ash, it is irregular, along with aggregation of both amorphous 
structures and polycrystalline. Small irregular fly ash particles are always made up of amorphous tinier particulates. This structure makes the fly ash strong adsorption capacity on heavy metals, dioxin and other pollutants.

(5) Crystalline phases analysis indicated that the fly ash mainly consists of some soluble salts like $\mathrm{KCl}, \mathrm{NaCl}$ and some crystals as $\mathrm{SiO}_{2}$ and $\mathrm{CaSO}_{4}$. The crystalline phases of heavy metals were usually below the detection limits of XRD and couldn't be identified effectively.

\section{ACKNOWLEDGEMENTS}

This work was funded by China Natural Science Foundation Project (Project No. 51378332) and Tianjin Enterprise Postdoctoral Innovation Project Merit Funding Plan (Grant No. 2015-009).

\section{REFERENCES}

A. Zacco, L. Borgese, A. Gianoncelli, et al: Environmental Chemistry Letters, vol. 12 (2014) no.1, p. 153-175.

F. Liu, J.G. Liu, Q.F. Yu, et al: Journal of Environmental Sciences, vol. 16 (2004) no. 6, p. 885-888.

K. Martin, P. Zbyšek, T. Vratislav, et al: Waste Management \& Research, vol. 30 (2012) no. 10, p. 1041-1048.

L. Zhang, X. Su, Z. Zhang, et al: Environmental Science and Pollution Research, vol. 21 (2014) no.22, p. 12767-12779.

R. Ibáňez, A. Andrés, J.A.Vguri, et al: Journal of Hazardous Materials, vol. 79 (2000) no. 3, p. 215-227.

X.G. Jiang, W. Chang: Journal of Zhejiang University of Technology, vol. 43 (2015) no. 1, p. 7-17. 